Amer. J. Bot. 70(7): 1079-1084. 1983.

\title{
DETECTION OF SILICA IN PLANTS ${ }^{1}$
}

\author{
P. Dayanandan, P. B. Kaufman, and C. I. Franklin \\ Division of Biological Sciences, University of Michigan, Ann Arbor, Michigan 48109
}

\begin{abstract}
A B S T R A C T
Silica in plants can be stained by silver chromate, methyl red, and a colorless crystal violet lactone which are adsorbed by the silanol groups resulting in red-brown, red, and blue colors, respectively. Specialized silica cells in grasses can also be detected through polarization colors due to form birefringence. Silica in the bulliform and silica cells of rice leaves is amorphous and is made up of $1-2-n m$ particles aggregating into $2.5 \times 0.4-\mu \mathrm{m}$ rods with oblique ends.
\end{abstract}

SILICON IS DEPOSITED in plants as hydrated amorphous silica $\left(\mathrm{SiO}_{2} \cdot \mathrm{nH}_{2} \mathrm{O}\right)$ through the polymerization of monosilicic acid $\left(\mathrm{Si}(\mathrm{OH})_{4}\right)$ absorbed by roots from soil solutions (Jones and Handreck, 1967). Molisch (1923) summarized five methods for the microscopic detection of silica in plants: 1) formation of sodium silicofluoride crystals by the action of $\mathrm{NaCl}$ and HF; 2) dry ashing; 3) wet ashing; 4) staining with basic fuchsin and malachite green; and 5) mounting in phenol. Netolitzky (1929) mentioned gentian violet, methylene blue, and safranin as additional stains for silica, but for lack of specificity, staining reactions were abandoned early (Viehoever and Prusky, 1938), and no color reaction is in current use. Wet ashing with acids (Parry and Smithson, 1958), microincineration to produce a spodogram of ash residues (Lanning, Hopkins and Loera, 1980) or clearing with phenol or other reagents have remained the only methods for the detection of silica by light microscopy. All these methods have tended to treat silica as an inert material, and investigators have resorted to differences in refractive indices (RI) of silica (RI 1.43) and the mounting media to render contrast. When mounted in phenol (RI 1.54) or Canada balsam (RI 1.54), cell walls and associated matter (RI 1.56) are obscured and silica is seen with higher relief.

We report here three distinct histochemical reactions based on the reactivity of the silanol $(\mathrm{SiOH})$ groups of silica. We also report the use of polarizing microscopy to impart diffraction colors for the detection of a special type of silica body in grasses. Ultrastructural information is also provided for the silica we have investigated.

\footnotetext{
${ }^{1}$ Received for publication 20 September 1982; revision accepted 14 February 1983.

We thank Dr. R. K. Iler for valuable suggestions, Dr. T. T. Chang for rice seeds, Mr. David Bay for photographic assistance and Nyacol Products Inc. for the gift of crystal violet lactone. This research was supported by the NSF Grant PCM 80-23923.
}

MATERIALS AND MICROSCOPY-The following species of rice (Oryza) obtained from the International Rice Research Institute, Los Baños, Philippines, and grown in clay in plastic pots in a growth chamber were the primary materials used in this investigation: $O$. alta Swallen, $O$. australiensis Domin, $O$. brachyantha A. Chev. et Roehr, $O$. eichingeri A. Peter, O. minuta J.S. Presl ex C.B. Presl, $O$. nivara Sharma et Shastry, $O$. officinalis Wall. ex Watt, $O$. perrieri A. Camus, $O$. punctata Kotschy ex Steud., O. rufipogon Griff., and $O$. sativa $\mathrm{L}$. Other silica accumulating monocots and dicots were used as supplementary material to confirm the applicability of the staining techniques to these other plants. Epidermal peels, free-hand sections, isolated cuticles and silica bodies were further treated as described under individual staining procedures. Since epidermal peels are not easy to isolate from rice leaves, about $1-\mathrm{cm}$-long pieces of fresh leaves were scraped on abaxial or adaxial sides to remove most of the cells above the underlying epidermis. Cuticle and silica bodies were isolated by immersing pieces of leaves in conc. $\mathrm{H}_{2} \mathrm{SO}_{4}$ for 1-4 days, and diluting with water to float the cuticles, and sediment the silica bodies. Cuticles were rinsed in water and transferred to slides for air drying. After several washings, the silica bodies were isolated by centrifugation or a long period of undisturbed sedimentation.

An Olympus VANOX research microscope with polarizing and epifluorescence optics was used. Color photographs were recorded either on Kodacolor II negative or Kodachrome 40 color transparency films. For transmission electron microscopy (TEM), rice leaves were fixed in $4 \%$ glutaraldehyde in $0.05 \mathrm{M}$ cacodylate buffer at $\mathrm{pH} 6.8$ overnight at $4 \mathrm{C}$. Either with or without post-fixation in $2 \% \mathrm{OsO}_{4}$ for $2 \mathrm{hr}$, they were dehydrated in an ethanol series and embedded in Spurr's medium. Isolated silica bodies were similarly embedded but were not 
fixed. Thin sections were collected on uncoated or holey-carbon coated 200-mesh copper grids. Sections were examined without staining or after staining with uranyl acetate and lead citrate. They were examined with a JEM $100 \mathrm{CX}$ electron microscope operated at $100 \mathrm{Kev}$.

METHODS AND RESULTS-Birefringent silica cells-Isolated cuticles of rice leaves often have silica cells attached to them. Such silica cells occur in 1-3 rows over the sclerenchyma associated with vascular bundles on both the abaxial and adaxial epidermises. When examined with polarized light with the polarizer and the analyzer in the conventional crossed positions (Bennett, 1950), the silica cells appear birefringent. When a 1st order plate of $530 \mathrm{~nm}$ is introduced with its slow axis running from SW to NE positions in the microscope field, the field appears uniformly red, and the silica cells show addition (blue) and subtraction (yellow) colors (Fig. 1-3). The resulting colors can be interpreted on the basis of the slow axis of the material responsible for birefringence running parallel to the outlines of the silica cells. Ultrastructural analysis of silica cells show (Fig. 12) numerous $2.5 \times 0.4-\mu \mathrm{m}$ rods of silica tightly packed inside each cell. These rods themselves are not responsible for the birefringence since their orientations do not parallel the expected arrangement. Also, the silica in these, as in all other parts of the rice plant, does not reveal any crystallinity when examined for electron diffraction. Figure 13 shows very fine lines about $10-20 \mathrm{~nm}$ thick, running parallel to the cell outlines. We interpret these to be impressions left by cellulose microfibrils since cellulose microfibrils are of these dimensions. Our unpublished observations suggest that during the ontogeny of a silica cell, the cell wall swells to fill a considerable portion of the cell lumen and that silica is polymerized around wall cellulose fibrils. Thus, the birefringence and the color of these silica cells are due to form birefringence caused by the impressions or concavities left by the microfibrils within the amorphous silica matrix. The birefringence is not due to intrinsic birefringence since silica is amorphous and any cellulose would have been digested by the conc. $\mathrm{H}_{2} \mathrm{SO}_{4}$ used in the isolation procedure. Silica bodies isolated from long epidermal cells and bulliform cells do not show the birefringence typical of the silica cells. This may indicate a basic difference in the ontogeny of different types of silica accumulating structures.

Silver-ammine chromate (SAC) reactionAmorphous silica reacts with the light-yellowcolored SAC producing red-brown-stained silica. The basis of this reaction is the adsorptive removal of ammonia which demasks the redbrown silver chromate from the masked yellow-colored solution. The silver chromate precipitates as reddish brown particles on the silica surface (Feigl, 1943). SAC is prepared by mixing solutions of $\mathrm{AgNO}_{3}$ and $\mathrm{K}_{2} \mathrm{CrO}_{4}$, washing the precipitate in hot water to remove soluble $\mathrm{KNO}_{3}$, and dissolving the $\mathrm{Ag}_{2} \mathrm{CrO}_{4}$ precipitate in less than the required amount of $\mathrm{NH}_{4} \mathrm{OH}$ to completely dissolve the precipitate. SAC solution exists in the following equilibrium: $\left(\mathrm{AgNH}_{3}\right)_{2} \mathrm{CrO}_{4} \rightleftharpoons 2 \mathrm{NH}_{3}+\mathrm{Ag}_{2} \mathrm{CrO}_{4}$. Excess ammonia interferes with efficient demasking of silver chromate by producing $\mathrm{CrO}_{4}{ }^{-}$ions which make the solution yellow in color. We prepare SAC by separately dissolving $34 \mathrm{~g}$ $\mathrm{AgNO}_{3}$ and $20 \mathrm{~g} \mathrm{~K}_{2} \mathrm{CrO}_{4}$ in $100 \mathrm{ml}$ of water each and mixing these solutions to obtain the precipitate. The precipitate is then washed in hot water (50-60 C) and dissolved in $200 \mathrm{ml}$ of $3 \% \mathrm{NH}_{3}(20 \mathrm{ml}$ of strong ammonium hy-

Fig. 1-11. Silica in Oryza species. 1-3. Silica cells attached to isolated cuticles of $O$. sativa cv. 'Basmati' photographed with polarizing microscope with $1 \mathrm{st}$ order red plate. The cuticles were isolated by immersing pieces of leaves in conc. $\mathrm{H}_{2} \mathrm{SO}_{4}$ for 3 days. All $\times 400$. 1. In conventional position with the slow axis of red plate oriented SW-NE. Length of leaf blade parallels the silica cell rows from left to right. 2. Portion of the same cells oriented at $45^{\circ}$ to the polarizer but silica cell rows parallel to the slow axis of red plate. 3. Same field oriented in the opposite direction as in Fig. 2 with rows at $90^{\circ}$ to the slow axis of red plate. 4. A row of silica cells of $O$. sativa cv. 'Homarenichiki' stained with SAC after $30 \mathrm{sec}$ etching. $\times 200$. 5. Silica body isolated from a bulliform cell of $O$. sativa cv. 'FR $13 A^{\prime}$ ' stained with SAC without etching. $\times 1,000.6$. MR-stained silica in a bulliform cell of $O$. alta viewed from the underside of adaxial epidermis. $\times 1,000$. 7. Silica from a bulliform cell of $O$. sativa cv. 'Nipponbare' lying on its side in an epidermal preparation stained with CVL. $\times 1,000.8$. Adaxial epidermis of $O$. officinalis stained with MR followed by CVL. Large bulliform cell silica bodies lie between rows of silica cells. $\times 100.9$. Abaxial cuticle with rows of silica cells still attached, from $O$. glaberrima stained with MR. Large papillae between the two vertical rows of silica cells lie over a major vascular bundle. These and other smaller papillae and protruberances around the stomata show silicification. $\times 200$. 10. C. S. of leaf of $O$. sativa cv. 'Basmati' showing upper epidermis with bulliform cell silica body stained with MR and adjacent tissues counterstained with fast green. $\times 1,000.11$. Similar to Fig. 10 but silica stained with CVL and adjacent tissues counterstained with safranin. $\times 1,000$. 

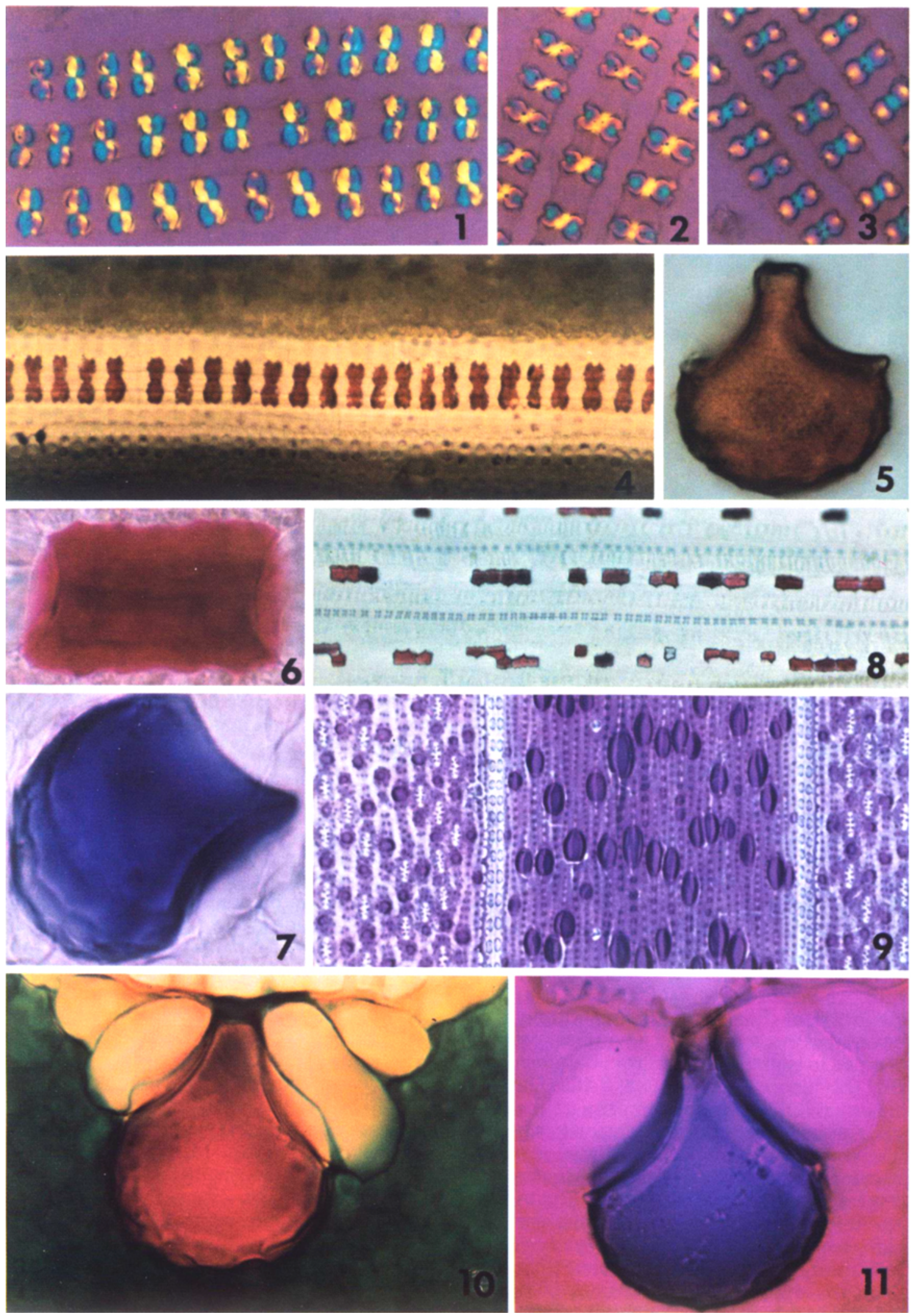

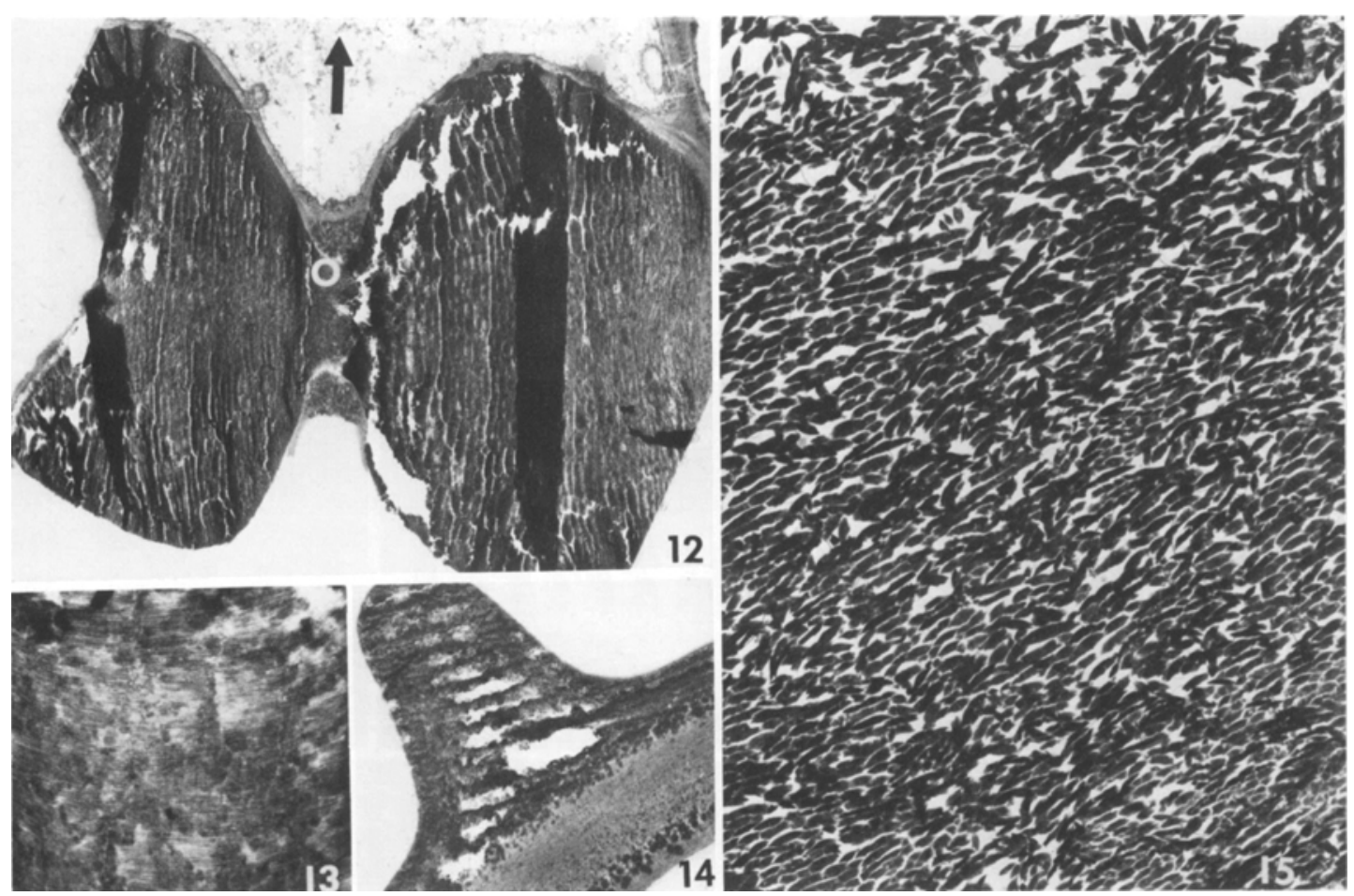

Fig. 12-15. Ultrastructure of silica in Oryza sativa. 12. Paradermal section of a silica cell from a leaf of cv. ' $\mathrm{L}-$ III-125' showing rods of silica. Dark bands are foldings that develop during sectioning. Arrow indicates the orientation of the longitudinal axis of leaf blade. $\times 7,200.13$. Portion of the silica cell in Fig. 12 (circle) at higher magnification showing impressions of cellulose microfibrils. $\times 29,760$. 14. C. S. of outer epidermal wall showing an inner and an outer layer of silica. The outer layer of silica is intimately associated with the cuticle and the papilla. When in association with the cell wall of outer epidermis, silica appears aggregated into spherical masses, unlike the typical rods seen when silica polymerizes in cell lumen. $\times 7,470.15$. C. S. of portion of an isolated silica body from 'Basmati' rice leaf bulliform cell. Individual rods of silica are about $2.5 \times 0.4 \mu \mathrm{m}$ in dimensions and each bulliform cell may contain as many as 100,000 such rods. Each rod is in turn made up of ultimate particles of $1-2 \mathrm{~nm}$ diam. $\times 5,435$.

droxide of $30 \% \mathrm{NH}_{3}$ in $190 \mathrm{ml}$ of $\mathrm{H}_{2} \mathrm{O}$ ). Filtered SAC can be stored at room temperatures in tightly stoppered bottles for a long time and can be refiltered when turbid.

Pieces of leaves with one surface scraped with a blade are dipped in $50 \% \mathrm{H}_{2} \mathrm{SO}_{4}$ for 2 min. After thorough washing, they are mounted in a few drops of SAC and immediately covered with a cover slip. Leaves can be further scraped to isolate the silica from bulliform cells (Fig. 5) before treating with SAC. The acid treatment enhances the intensity of the stain and results in the staining of more silica bodies. This may be due to partial digestion of the surrounding tissues to provide easy access of the reagent. However, any trace of excess acid leads to nonspecific precipitation since SAC can react with acids, acid salts, and acid anhydrides (Feigl, 1943). The above treatment does not always stain all the silica bodies because of the presence of tightly packed silica at the outer boundaries of the silica bodies that prevents entrance of SAC. Mild etching after acid treatment overcomes this problem (Fig. 4). Etching can be done with HF and/or ammonium fluoride $\left(\mathrm{NH}_{4} \mathrm{~F}\right)$. Since the silica bodies are very small, etching should be done carefully lest the entire silica body is dissolved. A $30-60$ sec etching in room temperature with $0.1-0.2 \% \mathrm{HF}$ with or without the addition of $\mathrm{NH}_{4} \mathrm{~F}$ to give a $1 \%$ concentration has given successful results with rice leaves. It is also possible to add the etching compounds directly in $\mathrm{H}_{2} \mathrm{SO}_{4}$. In all events, thorough washing is essential. SAC-stained material can be washed in water and dehydrated through an alcohol series and mounted in permanent mounting media. Dehydration changes color from redbrown to black offering excellent contrast for photomicrography.

Methyl red $(M R)$ and crystal violet lactone $(C V L)-$ Non-ionic MR and cationic CVL are readily adsorbed from non-polar solvents by 
amorphous silica gel. When dissolved in benzene, MR appears light yellow-orange in color, and CVL is colorless. When adsorbed by silica, MR imparts a bright red color, while CVL stains deep blue to violet. The commercial uses, chemical structure and basis of reaction of CVL have been described (Iler, 1979). Basically, in the absence of water, alcohol or other agents which tend to hydrogen bond with the $\mathrm{SiOH}$ groups on silica, the leucobasic CVL is adsorbed on the $\mathrm{SiOH}$ groups and undergoes a structural shift resulting in a change from colorless to blue. The adsorption of MR by the silanol groups on silica is the basis for the use of this dye in surface area measurements (Shapiro and Kolthoff, 1950).

Crystal violet lactone obtained from Nyacol Products Inc. (Megunco Road, Ashland, Massachusetts 01721 , USA) is used as a $0.1 \%$ solution in benzene. The acid form of MR (Kodak Co.) is used as a benzene-saturated and filtered solution. The acid form of MR is preferable to the sodium salt or the hydrochloride of MR. The latter two compounds do not stain silica as intensely as the acid form. If the hydrochloride of MR is used, it should be first dissolved in alcohol before the addition of benzene. Sections, peels, or small pieces of entire leaves are immersed in $50 \% \mathrm{H}_{2} \mathrm{SO}_{4}$ for $2-5$ min and rinsed in tap water. After dehydration through an ethanol or acetone series, they are transferred gradually to pure benzene, and from benzene, to MR or CVL. Color develops on the silica bodies almost immediately, but longer treatments ensure maximum intensity (Fig. $6,7)$. Isolated cuticles can be similarly processed (Fig. 9). Where handling the delicate cuticles is a problem, they can be allowed to dry on the slide, and CVL or MR applied directly. Excess MR or CVL should be removed by rinsing sections in pure benzene. Stained material can be made permanent by mounting in Permount (Fig. 6-11).

By mixing varying proportions of MR and CVL together, or by staining in CVL followed by MR or vice versa, intermediate shades of color can be imparted to silica bodies (Fig. 8). It is also possible to counterstain the non-silicified regions with a number of conventional stains. Figures 10 and 11 show counter-staining with fast green and safranin, respectively. These stains should be applied before transferring samples to ethanol-benzene mixture. Fast green is best applied in 100\% ethanol, while safranin can be applied while in water or $70 \%$ ethanol. Methyl red and CVL do not stain cellulose when applied in benzene. However, lignin, pectin-rich material, and calcium carbonate do stain with different intensities and shades of red or blue. When care is taken to completely dehydrate the material and remove all excess MR and CVL, these nonspecific staining reactions are minimized. Interfering components can also be selectively removed through treatments that do not dissolve silica.

With SAC reagent, the rods or aggregates of rods that make up silica in bulliform cells and silica cells, as well as in trichomes and lemma and palea of rice can be visualized. MR and CVL also stain silica deposited in long epidermal cells, trichomes, sclerenchyma, stomatal ledges, and epidermal papillae (Fig. 9). We have confirmed the presence of silica in these regions by $x$-ray microanalysis. In the outer wall of rice epidermis, silica is deposited in two distinct layers (Fig. 14). The outer layer of silica is in intimate contact with the cuticular layer and the numerous papillae characteristic of the rice epidermis (Fig. 9, 14). MR and CVL are excellent stains for isolated cuticle and associated siliceous matter in grasses. These staining reactions are applicable to all the species of rice mentioned in Materials and Microscopy. They readily reveal differences in size, distribution, degree of staining and number of silica bodies in these different species. For example, while most species of rices and cultivars of $O$. sativa possess silica cells only over the vascular bundles (Fig. 4), intercostal epidermal silica cells occur in $O$. minuta, $O$. perrieri and O. punctata.

A preliminary survey indicates that SAC, MR, and CVL also stain silica in other graminaceous and non-graminaceous plants. A large number of silica bodies in bulliform cells are revealed in Coix lacryma-jobi L. and in bamboos such as Phyllostachys sp., and Shibataea kumasasa Makino. Silica in the outer epidermal wall and in specialized thickenings of stomata in Equisetum are also stained. These stains also localize silica in the rings of cells at the bases of trichomes in the leaf epidermis of Humulus lupulus L., and in the epidermal trichomes of Commelina benghalensis L., Galium palustre $\mathrm{L}$. and Urtica dioica $\mathrm{L}$.

Discussion-The reactivity of silica is due to the presence of the silanol $(\mathrm{SiOH})$ groups, typically one silanol group per atom of silicon. Since biogenic silica is polymerized from silicic acid solutions under moderate temperatures, one could expect about 4-6 $\mathrm{OH} \mathrm{nm} \mathrm{nm}^{-2}$ of surface. The polymerization of biogenic silica into rodlike subunits (Fig. 15) offers large surface area for extensive chemical reactions. Since MR and CVL possess molecular areas of about 1.16 and $1.64 \mathrm{~nm}^{2}$, respectively, the surfaces of silica should have these minimum dimensions 
for the entry of these molecules. Most silica cells and some bulliform silica are not readily stained by MR and CVL unless etched. This may indicate that in some populations of silica bodies the outer surfaces are tightly packed with particles of silica that do not possess large enough pores for the molecules to enter. It may also mean that the silanol groups have been modified by other reactions such as esterification.

Positive results with SAC, MR, and CVL point to the similarity between biogenic silica and the numerous commercial silica gels that react similarly. Commercial silica is known to be highly reactive, capable of forming numerous ionic, nonionic and covalent bonds (Iler, 1979). It should be possible to develop many staining reactions that can be applied to biogenic silica. These could include direct visualization with stains such as Janus red and malachite green, deposits of metals such as cobalt, copper, nickel, silver, and zinc (Smith and Jacobson, 1956), and indirect staining of substances that are first adsorbed on the silica surface. Silica can also be visualized with fluorescence microscopy through the adsorption of a metal such as uranium or a stain such as rhodamine 6GB. Molisch (1923) indicated that silica mounted in phenol can show a reddish hue. The basis of this reaction can be attributed to the ability of silica to adsorb phenols (Davis, Deuchar and Ibbitson, 1973). Subsequent oxidation of phenol can lead to color development. It should thus be possible to adsorb phenols onto silica and to react with dizonium salts to produce the desired colors.

The physical and chemical similarities between commercial silica and biogenic silica allow one to take advantage of the extensive knowledge regarding the former to characterize the physical and chemical nature of biogenic silica, especially in connection with the level of hydration, pore size, pore volume, surface area, silanol number, and the presence of adsorbed metals and organic molecules. Such information will give us a better understanding of the functional and structural roles of silica in plants.

\section{LITERATURE CITED}

BenNeTt, H. S. 1950. The microscopical investigation of biological materials with polarized light. In R. M. Jones [ed.], McClung's handbook of microscopical technique, pp. 591-677. Hoeber Inc., New York.

Davis, K. M. C., J. A. Deuchar, AND D. A. Ibitson. 1973. Adsorption of phenols from non-polar solvents on to silica gel. J. Chem. Soc. Faraday Trans. I. 69: 1117-1126.

FeIGL, F. 1943. Laboratory manual of spot tests, pp. 155 156. Academic Press, New York.

ILER, R. K. 1979. The chemistry of silica, pp. 622-729. John Wiley \& Sons, New York.

JoNES, L. H. P., AND K. A. HANDRECK. 1967. Silica in soils, plants and animals. Adv. Agron. 19: 107-149.

Lanning, F. C., T. L. Hopkins, and J. C. Loera. 1980. Silica and ash content and depositional patterns in tissues of mature Zea mays L. plants. Ann. Bot. 45: 549-554.

Molisch, H. 1923. Mikrochemie der Pflanze, pp. 7476. Gustav Fischer, Jena.

Netolitzky, F. 1929. Die Kieselkörper die Kalksalze als Zellinhaltskörper. In $\mathrm{K}$. Linsbauer [ed.], Handbuch der Pflanzenanatomie, pp. 1-19. Gebrüder Borntraeger, Berlin.

ParRY, D. W., AND F. Smithson. 1958. Techniques for studying opaline silica in grass leaves. Ann. Bot. 22: 543-551.

Shapiro, I., AND I. M. Kolthoff. 1950. Studies on aging of precipitates and co-precipitation. XLIII. Thermal aging of precipitated silica (silica gel). J. Amer. Chem. Soc. 72: 776-782.

Smith, G. W., and H. W. Jacobson. 1956. Characteristics of adsorption complex metal-ammines and other complex ions of zinc, copper, cobalt, nickel, and silver on silica gel. J. Phys. Chem. 60: 1008-1012.

Viehoever, A., ANd S. C. Prusky. 1938. Biochemistry of silica. Amer. J. Pharm. 110: 99-120. 